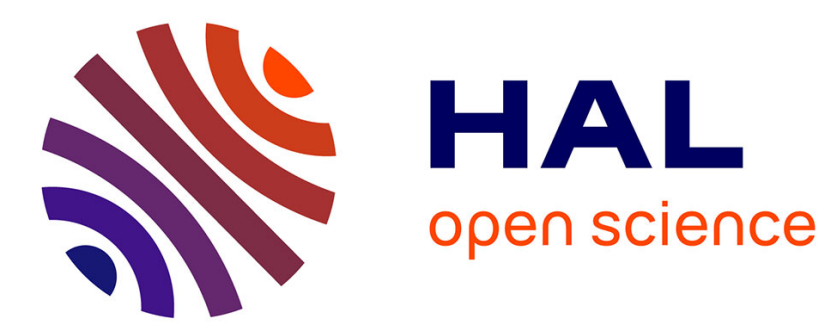

\title{
Efficiency Degradation Model of Lithium-ion Batteries for Electric Vehicles
}

\author{
Eduardo Redondo-Iglesias, Pascal Venet, Serge Pelissier
}

\section{To cite this version:}

Eduardo Redondo-Iglesias, Pascal Venet, Serge Pelissier. Efficiency Degradation Model of Lithiumion Batteries for Electric Vehicles. IEEE Transactions on Industry Applications, 2018, 55 (2), pp. 1932-1940. 10.1109/TIA.2018.2877166 . hal-01898906v2

\section{HAL Id: hal-01898906 https://hal.science/hal-01898906v2}

Submitted on 9 Oct 2019

HAL is a multi-disciplinary open access archive for the deposit and dissemination of scientific research documents, whether they are published or not. The documents may come from teaching and research institutions in France or abroad, or from public or private research centers.
L'archive ouverte pluridisciplinaire HAL, est destinée au dépôt et à la diffusion de documents scientifiques de niveau recherche, publiés ou non, émanant des établissements d'enseignement et de recherche français ou étrangers, des laboratoires publics ou privés. 


\title{
Efficiency Degradation Model of Lithium-ion Batteries for Electric Vehicles
}

\author{
Eduardo Redondo-Iglesias, Pascal Venet, Serge Pelissier
}

\begin{abstract}
The purpose of this paper is to analyse efficiency degradation of lithium-ion batteries. Two lithiumion cell technologies are considered under calendar ageing. It is well known that ageing mechanisms have an impact in cells' performances. Most of studies focus on capacity fade and impedance rise but efficiency is less frequently studied. However, from the application point of view, battery efficiency degradation directly impacts the system energy efficiency. Results reveal the importance of considering battery ageing in the design phase of electric vehicles, not only for capacity but also for efficiency reasons: efficiency degradation depends of the technology, so when comparing two technologies one must take into account the cells' performances not just when cells are fresh but during the whole lifespan. Another finding reported in this paper is the high correlation between capacity fade and energy efficiency for the tested technologies. Finally, two empirical models for energy efficiency degradation were developed in both technologies: the first one is based on Eyring relationships and the second one lies on the existing correlation between capacity fade and efficiency. Quality of each model is reported for both model types and battery technologies.
\end{abstract}

Index Terms-Efficiency model; Energy storage systems; Lithium-ion batteries; Accelerated ageing; Modelling

\section{INTRODUCTION}

Battery Electric Vehicles (EV) are much more efficient than ICE Vehicles (ICEV). EV's and ICEV's powertrain efficiency are about $70 \%$ and $20 \%$ respectively but this difference can significantly decrease when considering primary energy efficiency [1]. For this reason, every element in the energy conversion chain should be optimised: from power generation and distribution to vehicle energy use.

The battery is probably the most sensitive element in the EV powertrain system because of its cost and lifespan. Lithium-ion is nowadays the main technology

E. Redondo-Iglesias and S. Pelissier are with the Transport and Environment Laboratory, French Institut of Science and Technology for Transport, Developpement and Networks (IFSTTAR/AME/LTE), 69500, Bron, France (e-mail: eduardo.redondo@ifsttar.fr).

P. Venet is with Ampere Laboratory, Univ Lyon, Université Lyon 1, 69100, Villeurbanne, France.

All authors are with ERC GEST, France. for traction batteries because of its higher energy density and energy efficiency compared to previous existing technologies.

Ageing mechanisms are responsible of performance degradation of batteries: decrease of the amount of storable energy (capacity fade) and power availability (impedance increase). Depending on ageing path and battery composition, each ageing mechanism may act in a different magnitude. Hence, there is not always a direct correlation between impedance increase and capacity fade [2-4].

Within SIMCAL project a vast campaign of calendar ageing tests of commercial lithium-ion cells was conducted [5-12]. In [6], a study of capacity and impedance degradation of LFP cells from SIMCAL project is done. Some of these cells were analysed in post-mortem studies [8] demonstrating that main ageing mechanism is LLI (loss of lithium inventory) due to Solid Electrolyte Interphase(SEI) formation and growth.

In [13], a similar ageing campaign to SIMCAL was carried out: capacity and impedance were analysed. Postmortem studies confirmed that LLI was again the main ageing mechanism. An empirical capacity fade model with an Eyring relationship was developed. This model was validated with dynamic calendar ageing conditions (periods of different temperatures and states of charge). In [14] a combined cycling/calendar capacity fade model for LFP cells was developed.

On one hand, previous works on lithium-ion ageing dealt with modelling capacity fade [9, 12, 15-18], impedance rise $[2,7,19]$ or both $[11,20-23]$. On the other hand, some authors dealt with efficiency [24-26] and its dependence of current rate. But efficiency evolution throughout battery's lifespan was not often considered.

Some authors shown interest about efficiency evolution throughout battery's lifespan. For example, [10] made a first analysis of the performance evolution of cells from SIMCAL project. This analysis was made on a subset of SIMCAL ageing tests for each technology. Efficiency degradation was also mentioned in [27], where the authors included some values of energy efficiency for LFP cells for various current rates and states of ageing.

Battery efficiency is often considered in the design 
phase of vehicles, for example for battery sizing. This characteristic is age dependent: it will degrade over time like other characteristics (capacity, impedance, etc.). Efficiency varies over state-of-charge $(S o C)$, thus the battery use should be optimized to operate in the highest efficient $S o C$ levels. Consequently, for a better consideration, efficiency degradation over time must be taken into account.

In [28], the authors aimed to perform a life cycle analysis of LFP cells for use in second life application. The authors of this paper were interested in efficiency evolution of LFP cells, but a lack of efficiency evolution data led them to make the following assumption: efficiency evolution would follow the same trend that capacity fade. This is a very strong assumption: an efficiency degradation model would be a useful tool to obtain more precise results.

The present paper is an extended and updated version of the conference paper [29]. In this work, we intent to analyse all ageing tests from SIMCAL for two technologies (LFP and NMC). That includes 27 different combinations of $T$ and $S o C$ for two technologies.

In part II an analysis of efficiency as a function of $S o C$ is provided, this could be used to better assess the best $S o C$ regions to use depending on both ageing and efficiency.

In part III we develop an efficiency degradation model by two approaches: by using an Eyring relationship and by exploiting the existence of the correlation between capacity and efficiency fades.

A comparison of the results of two approaches of modelling is provided as a brief discussion about suitability of each considered lithium-ion technology depending of temperature for an example of application.

\section{MEASURING CAPACITY AND EFFICIENCY FADE}

\section{A. Experimental setup}

In the SIMCAL project, more than a hundred lithiumion cells from different manufacturers and positive electrode compositions were tested in calendar ageing [5]. The calendar ageing tests consisted in a full test matrix with three different temperatures and three different $S o C$ levels i.e. a full factorial design $3^{2}$ ( 2 factors, 3 levels per factor). Lithium-ion manufacturers recommend not to use this technology over $60^{\circ} \mathrm{C}$, thus this is the higher limit of temperature for ageing tests. Higher temperatures may induce thermal runaway even in rest conditions [30].

Accelerated ageing tests consisted in storing each cell at a fixed temperature $\left(30,45\right.$ or $\left.60^{\circ} \mathrm{C}\right)$ in a climate chamber at a fixed initial $S o C(30,65$ or $100 \%)$. Three

\section{ACRONYMS}

$\begin{array}{ll}\text { CC } & \text { Constant Current } \\ \text { CE } & \text { Coulombic Efficiency } \\ \text { CV } & \text { Constant Voltage } \\ \text { EV } & \text { Electric Vehicle } \\ \text { HEV } & \text { Hybrid Electric Vehicle } \\ \text { ICEV } & \text { Internal Combustion Engine Vehicle } \\ \text { LFP } & \text { Lithium Iron Phosphate } \\ \text { NMC } & \text { Nickel Manganese Cobalt } \\ \text { RPT } & \text { Reference Performance Test }\end{array}$

\section{NOMENCLATURE}

$\begin{array}{ll}D o D & \text { Depth of Discharge }(D o D(p . u .)=1-S o C(p . u .)) \\ I & \text { Cell current } \\ C & \text { C-rate }(1 \mathrm{C}=\text { current discharging the cell in } 1 \text { hour }) \\ O C V & \text { Open Circuit Voltage } \\ \operatorname{Pr} & \text { Probability } \\ Q & \text { Capacity } \\ S o C & \text { State of Charge } \\ T & \text { Temperature } \\ t & \text { time } \\ U & \text { Cell voltage } \\ W & \text { Energy (Work done) } \\ W_{n e t} & \text { Net energy } \\ \dot{W} & \text { Power } \\ \varepsilon & \text { Error (estimated value - measured value) } \\ \eta & \text { Efficiency } \\ \eta_{e n} & \text { Energy efficiency (cycle efficiency) }\end{array}$

\section{SUBSCRIPTS, SUPERSCRIPTS AND ACCENTS}

$\begin{array}{ll}x_{0} & \text { Initial value of } x \\ \hat{x} & \text { Estimated value of } x \\ \bar{x} & \text { Mean value of } x \\ x_{F} & \text { Fade of } x \text { (current value - initial value) } \\ x_{\text {charge }} & x \text { during charge } \\ x_{\text {discharge }} & x \text { during discharge }\end{array}$

cells were tested at each test condition for each lithiumion technology in order to improve the representativeness of results. Two technologies were tested: NMC cells are from Kokam (SLPB 70205130P, 12Ah pouch cells), whereas LFP cells are from A123 (ANR26650M1A, 2.3Ah, cylindrical cells).

The cells' characteristics were periodically measured at $25^{\circ} \mathrm{C}$ by the means of RPT (Reference Performance Test) using Biologic potentiostats with electrochemical impedance spectroscopy capability. RPT's (figure 1) are composed of 4 phases:

(A) a full discharge to measure the remaining charge in the cell,

(B) two full-charge/full-discharge cycles to measure the cell capacity,

(C) a partial-discharge/partial-charge cycle with cell impedance measurements at $5 \mathrm{SoC}$ levels,

(D) a full charge followed by a partial discharge to restore the $S o C$ to a value in agreement with the ageing test conditions. 

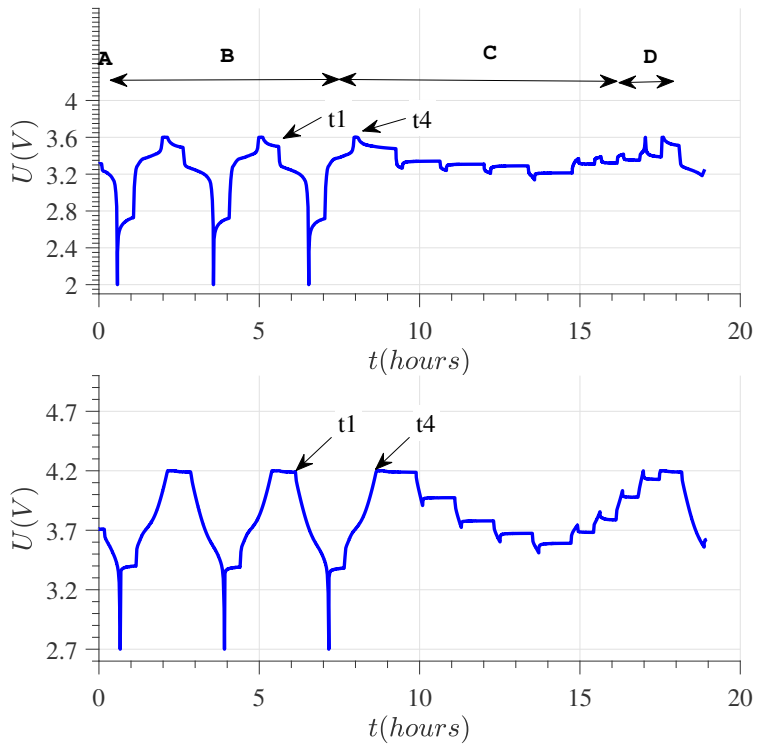

Figure 1: Voltage during first RPT for LFP (up) and NMC (bottom) cells.

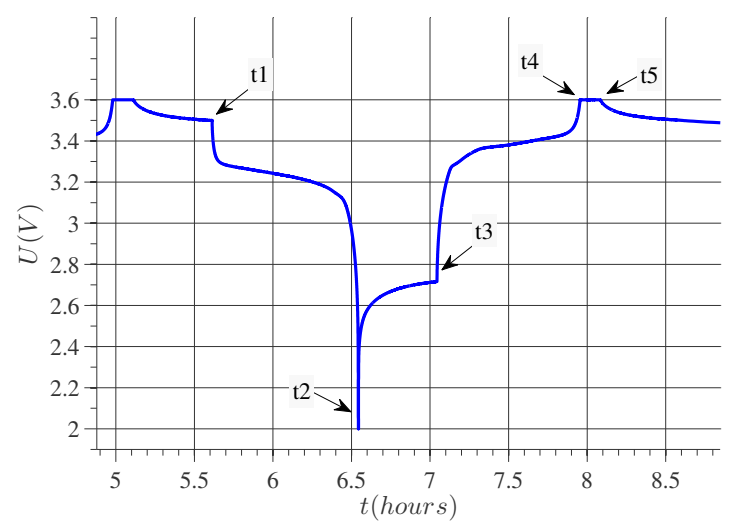

Figure 2: Zoom in last cycle (LFP cell).

\section{B. Methodology to measure efficiency}

Efficiency can be measured by several ways. The most common one consists in calculating the whole cycle efficiency of a full-charge/full-discharge cycle. For example, the International Organization for Standardization (ISO) defines a protocol to characterize efficiency in this way [31].

US-DOE (the United States Department of Energy) method [32] is based on the performance of 100 charge balanced power profiles at specified $S o C$ s. Any variation in the $S o C$ of the batteries under test enables to estimate the energy efficiency at this specified $S o C$. The main disadvantages of this method are the test duration and the difficulty to avoid excessive $S o C$ drift during the tests.

Kang et al. [24] proposed a method to measure efficiency of battery cells under constant current (CC) charges or discharges. This method lies on the definition of the net energy of a cell as a function of $I, O C V$ (open circuit voltage) and $S o C$.

Firstly, $O C V$ must be characterized by a pseudo$O C V$ or an incremental- $O C V$ approach [33]. Pseudo$O C V$ is obtained by cycling the battery at very low current rates and averaging $U_{\text {charge }}$ and $U_{\text {discharge. }}$ Incremental- $O C V$ is obtained by partial charges and discharges followed by rest periods.

Once $O C V$ as a function of $S o C$ is known, net energy is easily obtained by integration :

$$
W_{n e t}=\int_{S o C_{i}}^{S o C_{f}} I \cdot O C V \cdot d S o C
$$

- Charge and discharge energy are obtained in the same way with $U_{\text {charge }}$ and $U_{\text {discharge }}$ respectively:

$$
\begin{gathered}
W_{\text {charge }}=\int_{S o C_{i}}^{S o C_{f}} I \cdot U_{\text {charge }} \cdot d S o C \\
W_{\text {discharge }}=\int_{S o C_{i}}^{S o C_{f}} I \cdot U_{\text {discharge }} \cdot d S o C
\end{gathered}
$$

Finally, charge and discharge energy efficiencies are the relation between charge and discharge energy and net energy [24, 25]:

$$
\begin{aligned}
\eta_{\text {en,charge }} & =\frac{W_{\text {net }}}{W_{\text {charge }}} \\
\eta_{\text {en,discharge }} & =\frac{W_{\text {discharge }}}{W_{\text {net }}}
\end{aligned}
$$

Energy efficiency of a battery under charge and discharge can be expressed as:

$$
\eta_{\text {en }}=\eta_{\text {en, charge }} \cdot \eta_{\text {en,discharge }}=\frac{W_{\text {discharge }}}{W_{\text {charge }}}
$$

RPT design in SIMCAL project was originally intended for measuring capacity and impedance, not for efficiency. In this work, we analyse efficiency in a similar way to [24]. Unlike Kang's method, we do not attempt to separate charge and discharge efficiencies because SIMCAL RPTs do not offer a reliable measure for OCV (absence of pseudo-OCV phase), i.e. we focus on battery efficiency (equation 6).

For each RPT, the efficiency of last discharge-charge cycle (figure $1, t_{1}$ to $t_{4}$ ) is calculated. From $t_{1}$ to $t_{2}$ battery is discharged with $\mathrm{CC}$ at $1 \mathrm{C}$, from $t_{2}$ to $t_{3}$ battery is in rest condition and from $t_{3}$ to $t_{4}$ battery is charged with $\mathrm{CC}$ at $1 \mathrm{C}$ (figure 2). Obviously, full charge is not reached during $\mathrm{CC}$ charges and a subsequent $\mathrm{CV}$ 
(constant voltage) phase is performed from $t_{4}$ to $t_{5}$ to ensure full charging of the cell. We will only consider $\mathrm{CC}$ phases for efficiency $\left(t_{1}\right.$ to $\left.t_{4}\right)$.

Efficiency obtained by equation 6 is the average efficiency over a charge/discharge cycle. But in many applications such as electrical vehicles (EV) and hybrid electrical vehicles (HEV), batteries are often used in a partial $S o C$ zone. As $S o C$ is an important factor of battery ageing, efficiency characterisation as a function of $S o C$ is necessary. This would help to determine the best $S o C$ zone to operate in optimal conditions of energy efficiency and minimal ageing. Equation (7) expresses efficiency as a function of $S o C$ :

$$
\eta(S \circ C)=\frac{\left|\dot{W}_{\text {discharge }}(S o C)\right|}{\left|\dot{W}_{\text {charge }}(S o C)\right|}
$$

As in each RPT charge and discharge current rates are equal (1C), equation (7) can be simplified [29]:

$$
\eta(S o C)=\frac{U_{\text {discharge }}(S o C)}{U_{\text {charge }}(S o C)}
$$

Equation (8) is an approximation to power efficiency as the ratio between $U_{\text {discharge }}$ and $U_{\text {charge }}$. This equation is valid for applications such as battery pack dimensioning or battery technology benchmarking. For a fine estimation of energy losses, other models are more suitable like, for example, equivalent circuit models.

\section{Experimental results}

Figure 3 shows charge and discharge curves of these two cells and efficiency calculated by eq. (8), obtained from the first RPT (fresh cells). Efficiency of NMC cells is monotonically increasing with $S o C$. In contrary, LFP cells' efficiency decreases rapidly in the extremities (0 and $100 \%$ SoC). LFP efficiency has also a local minimum at $30 \% \mathrm{SoC}$.

Figure 4(a) shows the efficiency versus $S o C$ for a $\mathrm{NMC}$ cell during ageing at $60^{\circ} \mathrm{C}$ and $100 \% \mathrm{SoC}$. At the beginning of ageing tests mean efficiency was $96 \%$, but after 190 days the mean efficiency went down $87 \%$ and the capacity fade reached $37 \%$.

Ageing tests were carried on LFP cells during 378 days (figure 4(b)). Despite of capacity fade, efficiency was almost constant during the ageing tests: initial efficiency was $95 \%$ and decreased only $1 \%$ (to $94 \%$ ) at end of life.

\section{Discussion on experimental results}

In this work we have considered two different lithiumion technologies: NMC and LFP. NMC batteries have several advantages compared to LFP, mainly they have a

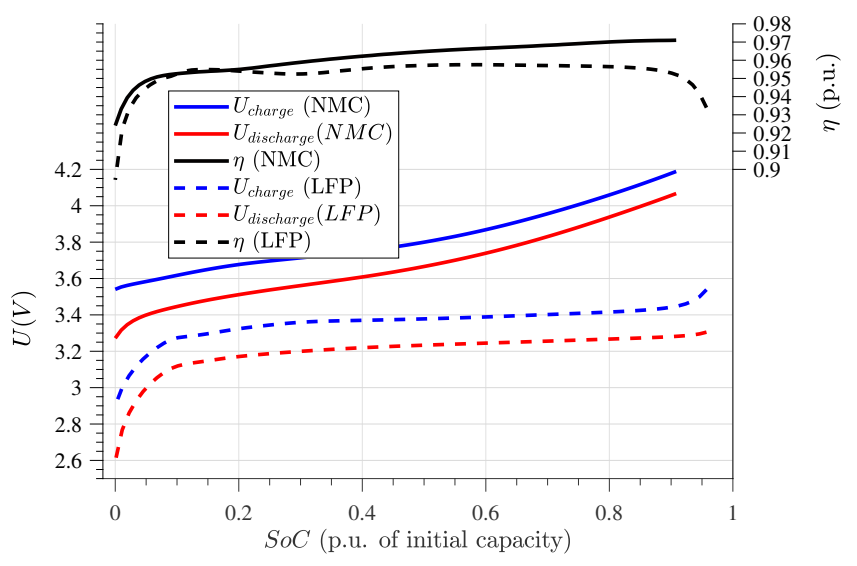

Figure 3: Charge and discharge voltages (left y-axis) and efficiency (right y-axis) of fresh cells.

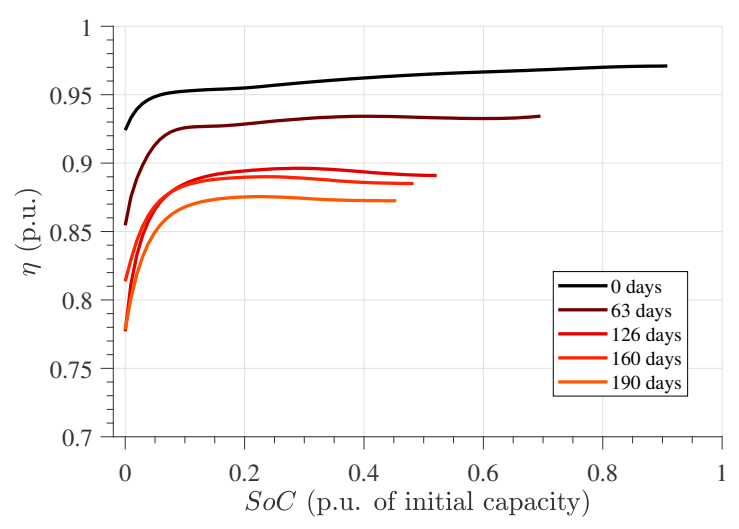

(a) NMC

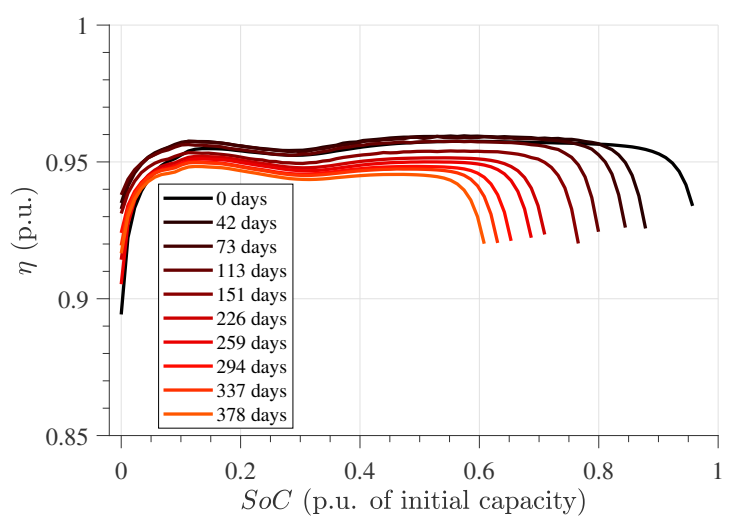

(b) LFP

Figure 4: Efficiency degradation of cells under calendar ageing conditions $\left(60^{\circ} \mathrm{C}, 100 \% \mathrm{SoC}\right)$.

higher energy density (125 and $106 \mathrm{kWh} / \mathrm{kg}$ respectively for the considered cells in this paper). However, LFP batteries are good candidates for long life and high current rate applications.

Power efficiency $(\eta(S o C))$ was calculated for both technologies at different states of degradation. The res- 
ults reveal that the shape and degradation rate of $\eta(S o C)$ are very different depending of technology. Efficiency appears to degrade much faster in NMC cells than in LFP cells. For example, for $60^{\circ} \mathrm{C}$ and $100 \%$ SoC (figure 4), we can see that NMC efficiency decreases under $90 \%$ after 120 days while LFP efficiency stays much less significant even after 300 days.

Concerning the shape of $\eta(S o C)$ (figure 3), in NMC cells it is monotonically increasing with $S o C$. In LFP we can discern three regions: at lower $S o C$ levels efficiency decreases rapidly; at medium $S o C$ s efficiency is mainly flat with a local minimum at approximately $S o C=30 \%$; finally, at higher $S o C$ s efficiency decreases again.

The main reason behind the existing difference in shape of $\eta(S o C)$ is the difference in shape of positive electrode equilibrium potentials (both negative electrodes are graphite based).

On one hand, NMC electrode's potential is monotonically decreasing with the proportion of lithium, i.e. it is monotonically increasing with $S o C$. As charge and discharge voltage curves of NMC cells are increasing with $S o C$ and the distance between them is quite constant (see figure 3), $\eta(S o C)$ increases with $S o C$ (equation 8).

On the other hand, LFP electrode's potential is constant at approximately $3.43 \mathrm{~V}$ vs. $\mathrm{Li}^{+}$except in very low $\mathrm{SoC}(<5 \%)$ and very high $\mathrm{SoC}(>95 \%)$ [34]. Graphite electrode's potential decreases rapidly in the first stages of lithiation (low proportion of lithium, lower $S O C$ s) and it decreases slowly from 0.13 to $0.08 \mathrm{~V}$ vs. $\mathrm{Li}^{+}$in the last stages of lithiation (from 20 to $100 \% S o C$ ) $[35,36]$. LFP-graphite cell's OCV is the difference between LFP's and graphite's potentials, so in the medium $S o C$ s OCV increases slowly from 3.3 to $3.35 \mathrm{~V}$. As charge and discharge voltages follow the same trends, $\eta(S o C)$ is mainly flat from $S o C=10$ to $90 \%$ (figure 3).

The local minimum of $\eta(S o C)$ found at $S o C=30 \%$ in LFP cells is probably due to a graphite phase transition (from $\mathrm{LiC}_{12}$ to $\mathrm{LiC}_{6}$ ) [35, 36]. This phase transition also occurs in NMC cells because they have also a graphite negative electrode, but it is not reflected in $\eta(S o C)$ by a local minimum because the NMC positive electrode potential is not constant with $S o C$.

\section{ModelLING CAPACITY AND EFFICIENCY FADE}

Energy and power capabilities of lithium-ion batteries degrade over time in calendar ageing as a function of $S o C$ and $T$. Energy and power degradation can be assimilated respectively to capacity and efficiency fade $\left(Q_{F}\right.$ and $\left.\eta_{F}\right)$. In previous works $[12,37]$ capacity fade of lithium-ion cells in calendar ageing has been modelled by using the Eyring relationship.
The Eyring relationship extends the Arrhenius law (temperature dependence) to other stress factors (e.g. pressure, current, voltage, etc.). Equation (9) is a general form for a performance $(y(t))$ degrading over time under two type of stresses ( $T$ and $S_{i}$ ):

$$
y\left(t, T, S_{i}\right)=A \cdot T^{n} \cdot e^{\left(E_{a} / k T+B_{i} S_{i}+C_{i} S_{i} / k T\right)} \cdot f(t)
$$

In the Eyring relationship, the influence of each additional stress $\left(S_{i}\right)$ is added to the exponential function beside the thermal stress term $\left(E_{a} / k T\right)$. The direct influence of a stress is $B_{i} S_{i}$ while $C_{i} S_{i} / k T$ represents an interaction term between $T$ and $S_{i}$. The model parameters are: $A, n, E_{a}, B_{i}$ and $C_{i}$, with $k$ the Boltzmann constant and $f(t)$ the time degradation function of $y(t)$.

In battery ageing, $f(t)$ is typically a power of time (e.g. $t, \sqrt{t}$ ) or a linear combination of both functions $(a t+b \sqrt{t})$. In calendar ageing of batteries, $S_{i}$ can be $S o C$ or $D o D$. Both quantities can be calculated relative to initial or current capacity $\left(Q_{0}\right.$ or $\left.Q\right)$. For comparability and simplicity reasons, in this work as for [37] we chosen $S_{i}=D o D$, with $D o D$ relative to $Q_{0}$.

As shown in figure 5, we can imagine two approaches to model efficiency and capacity fades: the first one consists in considering separate models (figure 5(a)). The inputs of both sub-models are $T$ and $D o D$.

The second approach is to model capacity fade and then to model efficiency evolution as a function of capacity fade (figure 5(b)). In this approach, the ageing model is composed of two sub-models: a capacity fade model and a efficiency fade model. The inputs for the capacity fade model are $T$ and $D o D$. The input for the efficiency model is the estimated capacity fade $\left(\hat{Q}_{F}\right)$.

\section{A. Eyring capacity fade model}

Here, the main assumption is the linear evolution of $Q_{F}$ with the time (t) when the stress factors $(T, D o D)$ are constant. This is equivalent to consider

$$
Q_{F}=C_{A}(T, D o D) \cdot t
$$

where $C_{A}$ is the acceleration coefficient depending of the stress levels [37].

In this work, we will consider a modified Eyring relationship to model $C_{A}$ (from [37]):

$$
\hat{Q}_{F}=\left(A \cdot e^{\left(\frac{-E_{a}}{k \cdot T}+B \cdot D o D+\frac{C \cdot D o D}{k \cdot T}\right)}-D\right) \cdot t
$$

Finally, the capacity evolution is obtained by subtracting the estimated capacity fade $\left(\hat{Q}_{F}\right)$ from the initial value of the capacity $\left(Q_{0}\right)$ :

$$
\hat{Q}(t, D o D, T)=Q_{0}-\hat{Q}_{F}(t, D o D, T)
$$




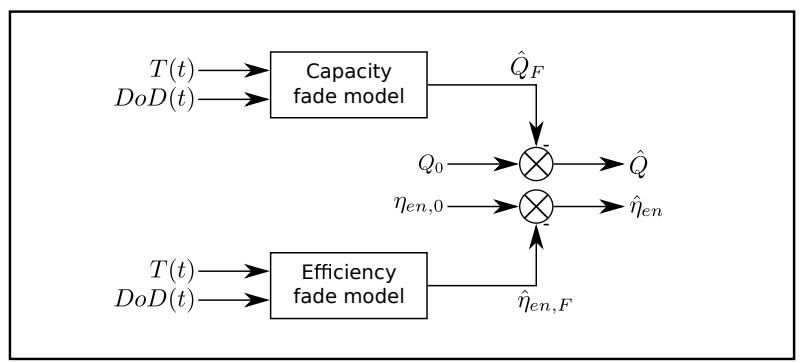

(a)

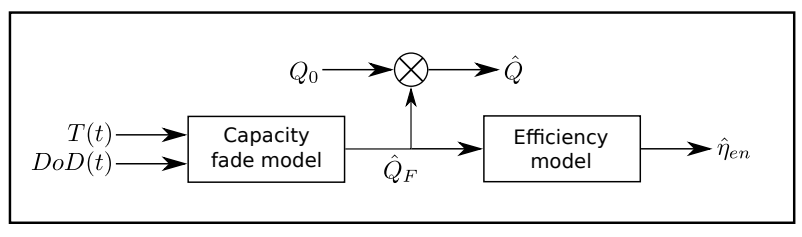

(b)

Figure 5: Two approaches to modelling: (a) separate models (b) efficiency as a polynomial of capacity fade.

\section{B. Eyring efficiency fade model}

The efficiency ageing model can be formulated in the same way as the capacity ageing model:

$$
\begin{gathered}
\hat{\eta}_{e n, F}=\left(A_{\eta} \cdot e^{\frac{-E_{a \eta}}{k \cdot T}+B_{\eta} \cdot D o D+\frac{C_{\eta} \cdot D o D}{k \cdot T}}-D_{\eta}\right) \cdot t \\
\hat{\eta}_{e n}(t, D o D, T)=\eta_{e n, 0}-\hat{\eta}_{e n, F}(t, D o D, T)
\end{gathered}
$$

\section{Polynomial efficiency model}

Figure 6 shows the cycle efficiency versus capacity fade for both technologies (NMC and LFP) and for all the storage conditions. We can see that efficiency mainly depends of capacity fade and the type of cell (NMC or LFP): a strong correlation between capacity fade and efficiency degradation exists.

In this approach, efficiency is formulated as a polynomial of the capacity fade:

$$
\hat{\eta}_{e n}\left(\hat{Q}_{F}\right)=\sum_{i=0}^{n} a_{i} \cdot \hat{Q}_{F}^{i}
$$

where capacity fade is estimated from eq. (11).

In this work we have chosen second degree polynomials for LFP cells and first degree polynomials for NMC cells.

The obtained model parameters for each model are in table I. For each model, the parameter set has been identified with a least square minimisation of the difference between model estimations and measurements.

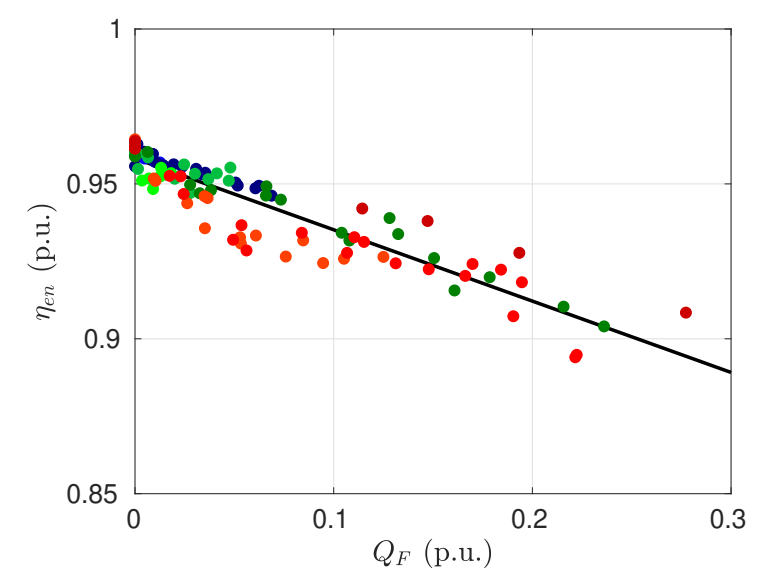

(a)

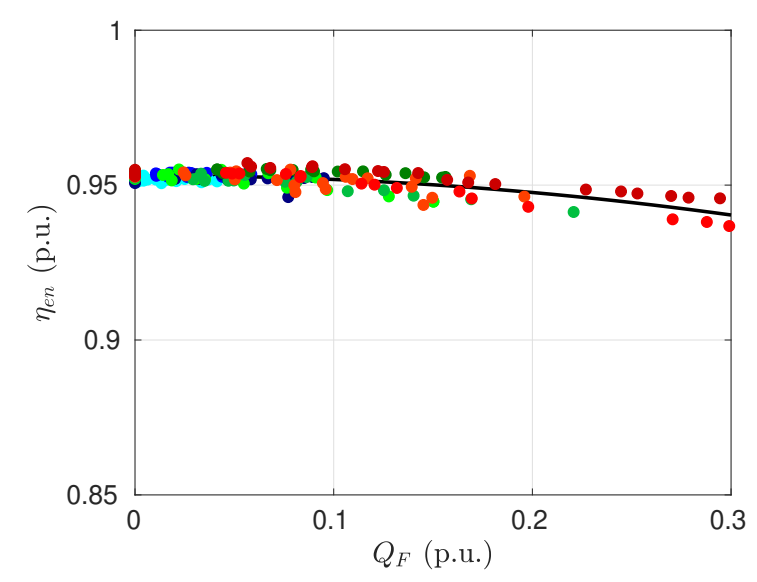

(b)

Figure 6: Efficiency versus capacity fade (a) NMC cells, (b) LFP cells. Points are measurements at different ageing conditions: red, green and blue for 60,45 and $30^{\circ} \mathrm{C}$ respectively, colour shades indicate SoC (30, 65 and $100 \%$ from light to dark). The polynomial approximation is represented by a black continuous line.

\section{Modelling results}

Figure 7 illustrates some simulations compared to measurements of capacity and efficiency. In this example, three simulations where performed at three $S o C$ levels: 30,60 and $100 \%$ at $45^{\circ} \mathrm{C}$ for both cell types.

For NMC (figure 7(a)) some cells seem to regenerate their capacity (i.e. negative capacity fade) at the beginning of the tests (e.g. $S o C=65$ or $30 \%$ for $T$ $=45^{\circ} \mathrm{C}$ ). As explained in [37], this phenomenon is probably due to an initial decrease of impedance in the firsts stages of SEI formation. Capacity measurements are strongly dependent of impedance when they are performed at medium/high rates as in SIMCAL project (1C). By performing capacity measurements at low rates, for example $\mathrm{C} / 5$ or lower, distortion due to this initial decrease of impedance is minimised [38, 39]. 


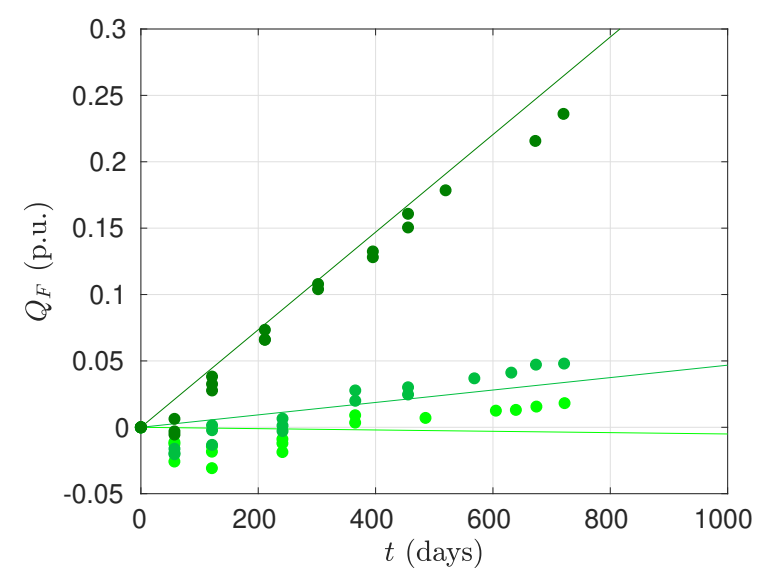

(a) NMC cells, capacity fade

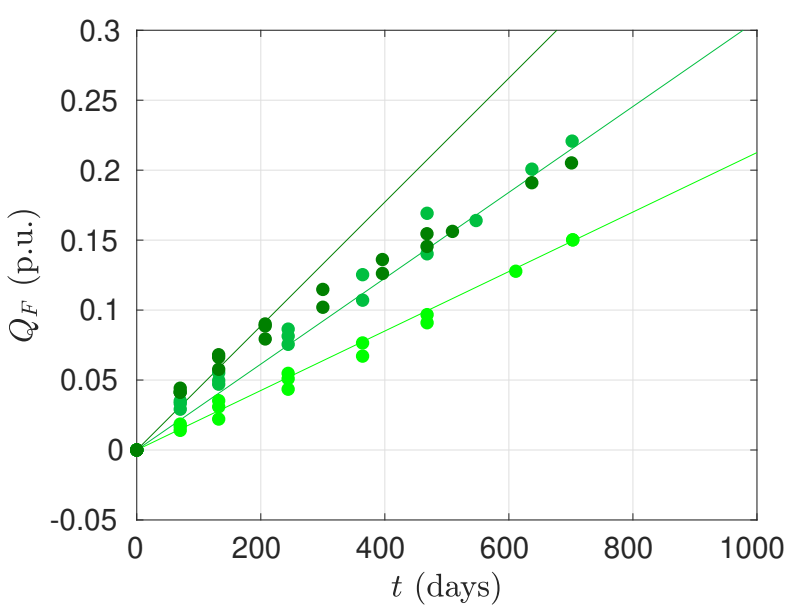

(c) LFP cells, capacity fade

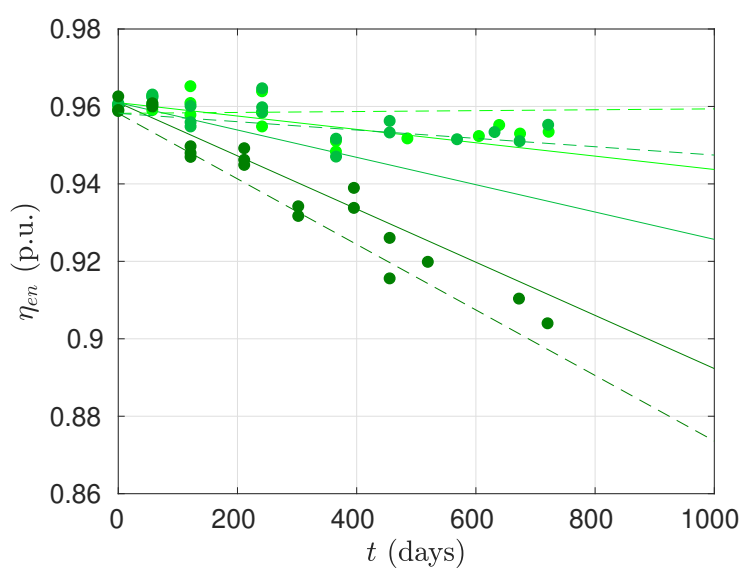

(b) NMC cells, efficiency

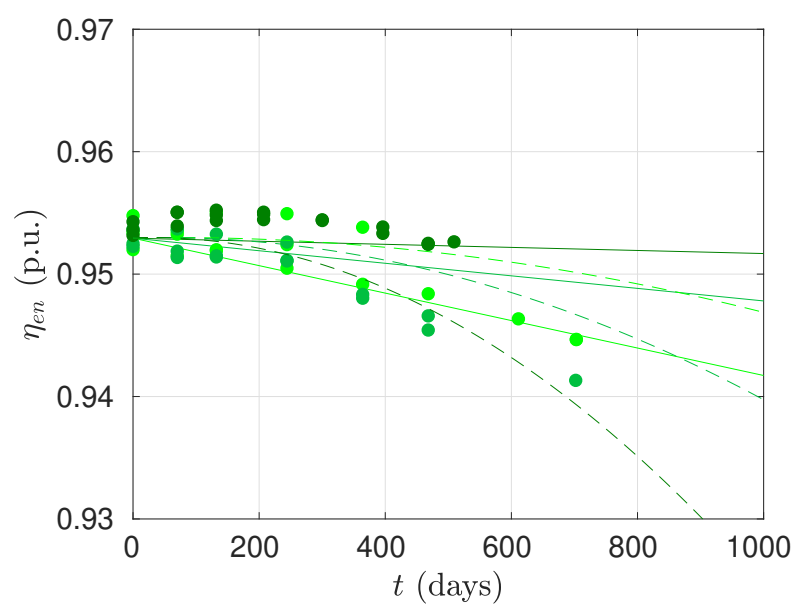

(d) LFP cells, efficiency

Figure 7: Results of ageing at $45^{\circ} \mathrm{C}$. (a) Capacity fade and (b) efficiency versus time of NMC cells. (c) Capacity fade and (d) efficiency versus time of LFP cells. Points are measurements, continuous lines are simulations of $Q_{F}$ and $\eta_{e n}$ Eyring models, dashed lines are simulations of $\eta_{e n}$ polynomial model. Colour shade indicates $\operatorname{SoC}(30,65,100 \%)$ from light to dark.

In this example $\left(T=45^{\circ} \mathrm{C}\right)$, the model overestimates capacity fade at $S o C=100 \%$ for LFP cells (figure 7(c)). Notice that this couple of ageing conditions represent the worst case for this model in terms of precision. As shown in table II, overall quality of LFP's $Q_{F}$ model is good (mean absolute error of $1.3 \%, R^{2}>0.9$ ).

Results shown in figure 7(b) and 7(d) reveal that the different approaches of efficiency modelling (Eyring relationship versus polynomial of capacity fade) have different behaviours.

For example, for NMC cells (figure 7(b)), the efficiency fade (and also the capacity fade) is quite similar at lower levels of $S o C(30,65 \%)$ being much faster at $100 \% \mathrm{SoC}$. In this example, the model based on a polynomial of $Q_{F}$ is better compared to the Eyring based one. The reason is that the polynomial based efficiency model fits in the same manner that capacity fade: that is degradation at $100 \% \mathrm{SoC}$ is much faster than at other $S o C$ levels. On the other hand, when performing simulations with the Eyring based efficiency model, the differences between $S o C 100 \%$ and the lower $S o C$ levels $(30,65 \%)$ are less significant than for the polynomial one.

For LFP cells (figure 7(d)), the errors of efficiency simulations are comparable for both approaches (Eyring versus polynomial). However, while the polynomial model leads to parabolic evolutions, the Eyring efficiency model leads to linear evolutions that can diverge from measurements with time.

Figure 8 shows the cumulative distribution of errors $\operatorname{Pr}(|\varepsilon|)$ for all simulations at the nine possible combinations of $T\left(30,45,60^{\circ} \mathrm{C}\right)$ and $S o C(30,65$, $100 \%$ ) for both technologies (NMC, figure 8(a) and LFP, figure $8(\mathrm{~b})$ ). This figure confirms that both approaches to efficiency fade modelling have a similar precision.

More detailed results about the quality of these models can be found in table II. The mean absolute errors $\overline{|\varepsilon|}$ of the capacity fade model simulations are $1.48 \%$ and 


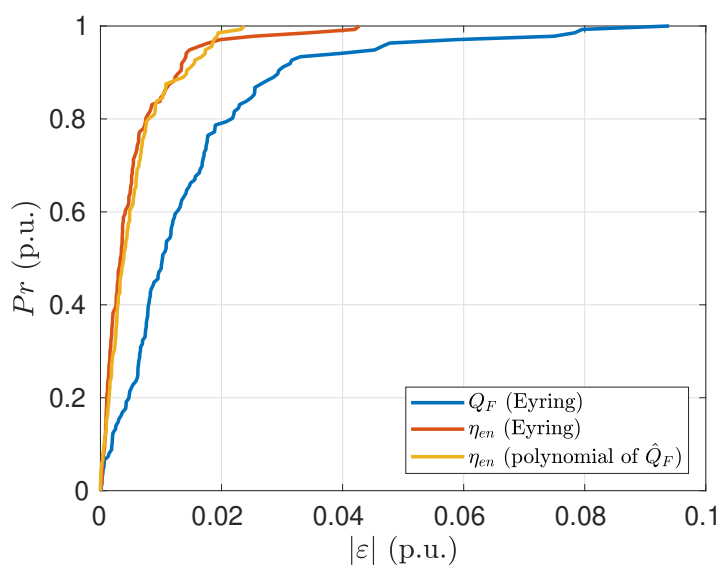

(a) $\mathrm{NMC}$

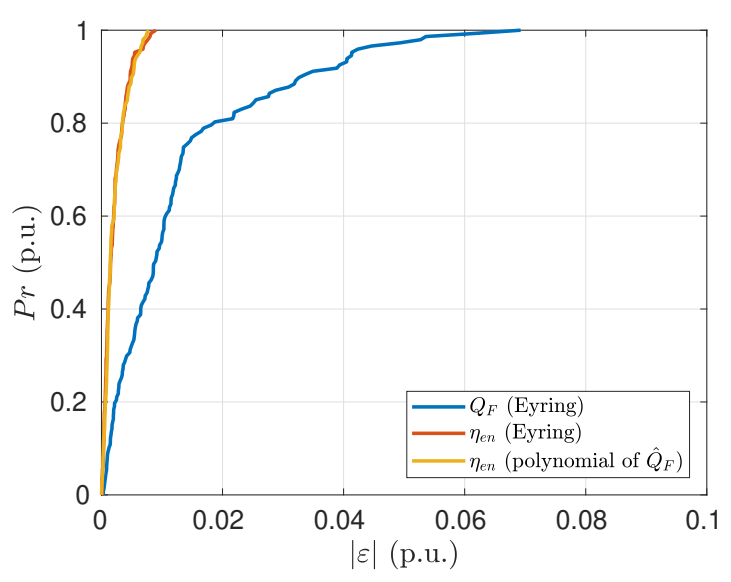

(b) LFP

Figure 8: Cumulative distribution of errors.

$1.28 \%$ for the NMC and the LFP cells respectively and $R^{2}$, the coefficients of determination, are 0.895 (NMC) and 0.925 (LFP). These two quantities confirm that the precision of the capacity fade model is satisfactory.

For NMC cells the polynomial model of efficiency is more satisfactory than the Eyring based one. At higher values of $\operatorname{Pr}$ (probability), the lowest absolute error corresponds to the polynomial model. The value of $R^{2}$ is also substantially higher for this model compared to the Eyring based model (table II.a).

For LFP cells the polynomial and the Eyring based models have both similar values of errors for each value of $\operatorname{Pr}$ and similar values of $R^{2}$ (table II.b). Notice that $R^{2}$ is very low (about 0.34 ) which indicates a bad quality of modelling for both types of models. In fact, as shown in figure 6(b), the efficiency fade is very low in LFP cells. The range of variation of the efficiency over the lifespan in LFP cells is of the same magnitude that the variability between different cells, which explains a lower value of $R^{2}$ compared to NMC cells.
Table I: Model parameters.

a. Eyring capacity fade model

\begin{tabular}{clll}
\hline Parameter & NMC cells & LFP cells & units \\
\hline \hline$A$ & $2.233 \cdot 10^{10}$ & $2.563 \cdot 10^{05}$ & (p.u./day) \\
$E_{a}$ & 0.8690 & 0.5531 & (eV) \\
$B$ & 37.19 & 12.34 & (n.u.) \\
$C$ & -1.162 & -0.3672 & (eV) \\
$D$ & $1.5 \cdot 10^{-05}$ & 0 & (p.u./day) \\
\hline
\end{tabular}

b. Eyring efficiency fade model

\begin{tabular}{clll}
\hline Parameter & NMC cells & LFP cells & units \\
\hline \hline$A_{\eta}$ & $1.419 \cdot 10^{10}$ & $1.428 \cdot 10^{08}$ & (p.u./day) \\
$E_{a \eta}$ & 0.9021 & 0.8412 & (eV) \\
$B_{\eta}$ & -8.371 & -11.78 & (n.u.) \\
$C_{\eta}$ & 0.1813 & 0.3585 & (eV) \\
$D_{\eta}$ & $4.0 \cdot 10^{-06}$ & $5.5 \cdot 10^{-06}$ & (p.u./day) \\
\hline
\end{tabular}

c. Polynomial efficiency model

NMC: $\quad \eta_{e n}\left(Q_{F}\right)=-0.2303 \cdot Q_{F}+0.9582$

LFP: $\quad \eta_{e n}\left(Q_{F}\right)=-0.1532 \cdot Q_{F}^{2}+0.003923 \cdot Q_{F}+0.9530$

Table II: Modelling results: mean absolute error $(\overline{|\varepsilon|})$, error for some probabilities of the cumulative distribution of errors $(|\varepsilon|(\operatorname{Pr}))$ and coefficient of determination $\left(R^{2}\right)$. The quantities are expressed in p.u.

a. NMC cells

\begin{tabular}{cccc}
\hline Model & $Q_{F}$ (Eyring) & $\eta_{e n}$ (Eyring) & $\eta_{e n}$ (polynomial) \\
\hline \hline$\overline{|\varepsilon|}$ & 0.0148 & 0.00541 & 0.00551 \\
$|\varepsilon|(P r=0.50)$ & 0.0102 & 0.00329 & 0.00385 \\
$|\varepsilon|(P r=0.90)$ & 0.0294 & 0.0130 & 0.0142 \\
$|\varepsilon|(P r=0.95)$ & 0.0455 & 0.0150 & 0.0175 \\
$|\varepsilon|(P r=0.99)$ & 0.0791 & 0.0393 & 0.0219 \\
$R^{2}$ & 0.895 & 0.701 & 0.774 \\
\hline
\end{tabular}

b. LFP cells

\begin{tabular}{cccc}
\hline Model & $Q_{F}$ (Eyring) & $\eta_{e n}$ (Eyring) & $\eta_{e n}$ (polynomial) \\
\hline \hline$\overline{|\varepsilon|}$ & 0.0128 & 0.00211 & 0.00215 \\
$|\varepsilon|(\operatorname{Pr}=0.50)$ & 0.00878 & 0.00151 & 0.00148 \\
$|\varepsilon|(P r=0.90)$ & 0.0329 & 0.00475 & 0.00503 \\
$|\varepsilon|(P r=0.95)$ & 0.0413 & 0.00548 & 0.0062 \\
$|\varepsilon|(P r=0.99)$ & 0.0580 & 0.00808 & 0.00743 \\
$R^{2}$ & 0.925 & 0.345 & 0.344 \\
\hline
\end{tabular}

\section{E. Discussion on modelling results}

In this part, two approaches for modelling capacity and efficiency degradation were presented.

The first approach is based on two independent Eyring relationships: capacity and efficiency are modelled separately as functions of time and ageing factors ( $T$ and $S o C$ ). Each Eyring relationship has 5 parameters, so for this approach 10 parameters are needed.

The second approach consist in taking advantage of the existing correlation between efficiency and capacity 
fades. In this approach, two models are cascaded: the output of the capacity fade model is used as input for the efficiency model. A polynomial relation $\eta\left(Q_{F}\right)$ has been identified from experimental data with 2 or 3 parameters depending of the technology. So for this model 7 to 8 parameters are needed.

The first approach is a priori supposed to be a better solution in terms of accuracy. Firstly, because of the higher number of parameters (higher degrees of freedom). Secondly, in the second approach capacity fade estimation errors are propagated to efficiency.

The quality of results where analysed for both approaches in both technologies. Figure 8 and table II show that there is no great difference in terms of quality between both approaches: mean errors of efficiency and their distributions are similar for NMC and LFP. Nevertheless, there is a difference in $R^{2}$ for NMC: 0.701 for the first approach, 0.774 in the second, indicating that second approach would have some benefit over the first one.

\section{CONCLUSIONS}

In one hand, efficiency of batteries is usually considered in the design phase, for example, of electric vehicles. On the other hand, capacity fade (sometimes also impedance rise) throughout the lifetime is often evaluated by the means of accelerated ageing tests. Nevertheless, efficiency evolution over lifespan is not often considered.

In this work, we intended to evaluate efficiency degradation in accelerated calendar ageing for two lithiumion technologies: NMC and LFP.

Constant current phases of full charge/discharge cycles allowed us to build the characteristic curves of efficiency over $S o C$ at each state of ageing. Characteristic curves reveal the best $S o C$ regions to operate in terms of efficiency. LFP showed a particular behaviour with a local minimum of efficiency at $30 \% \mathrm{SoC}$.

We also provide two approaches to efficiency degradation modelling: first one is based on the Eyring relationship and second one is based on a polynomial expression of capacity fade. The results of two approaches show that second approach can be more convenient for two reasons: simplicity (fewer number of parameters) and precision (similar or higher $R^{2}$ ).

Energy efficiency analysis within battery ageing offers a simple but effective way to assess the adequacy of batteries to an application during the whole lifespan. These type of models can be used as decisional tools in the design phase or in life cycle assessments of electric vehicles.

\section{ACKNOWLEDGEMENT}

This work uses data from SIMCAL project (20092012). SIMCAL project was funded by the French National Research Agency (ANR). SIMCAL partners are CEA, EDF, EIGSI, IFPEN, IFSTTAR, IMS, LEC, LMSImagine, LRCS, PSA, RENAULT, SAFT and VALEO.

\section{REFERENCES}

[1] M. Åhman, Energy, vol. 26, no. 11, pp. 973 - 989, 2001.

[2] I. Bloom, B. Cole, J. Sohn, et al., J. Power Sources, vol. 101, no. 2, pp. 238 - 247, 2001.

[3] J. Vetter, P. Novák, M. Wagner, et al., J. Power Sources, vol. 147, no. 1 - 2, pp. $269-281,2005$.

[4] K. L. Gering, S. V. Sazhin, D. K. Jamison, et al., J. Power Sources, vol. 196, no. 7, pp. 3395 - 3403, 2011.

[5] A. Delaille, S. Grolleau, F. Duclaud, et al. in ECS Meeting Abstracts, no. 14, (San Francisco), p. 1191, The Electrochemical Society, Oct. 2013.

[6] M. Kassem, J. Bernard, R. Revel, et al., J. Power Sources, vol. 208, pp. 296 - 305, 2012. SIMCAL.

[7] A. Eddahech, O. Briat, E. Woirgard, et al., Microelectronics Reliability, vol. 52, no. 9-10, pp. 2438 - 2442, 2012.

[8] M. Kassem and C. Delacourt, J. Power Sources, vol. 235 , pp. $159-171,2013$.

[9] S. Grolleau, A. Delaille, H. Gualous, et al., J. Power Sources, vol. 255, pp. 450-458, June 2014.

[10] A. Eddahech, O. Briat, and J.-M. Vinassa, Energy, vol. 84, pp. $542-550,2015$.

[11] I. Baghdadi, O. Briat, J.-Y. Delétage, et al., J. Power Sources, vol. 325, pp. 273 - 285, 2016.

[12] E. Redondo-Iglesias, P. Venet, and S. Pelissier, Journal of Energy Storage, vol. 13, pp. $176-183$, 2017.

[13] E. Sarasketa-Zabala, I. Gandiaga, L. RodriguezMartinez, et al., Journal of Power Sources, vol. 272, pp. $45-57,2014$.

[14] E. Sarasketa-Zabala, E. Martinez-Laserna, M. Berecibar, et al., Applied Energy, vol. 162, pp. $839-852,2016$.

[15] R. Spotnitz, J. Power Sources, vol. 113, no. 1, pp. $72-80,2003$.

[16] P. Ramadass, B. Haran, R. White, et al., J. Power Sources, vol. 123, no. 2, pp. 230 - 240, 2003.

[17] J. Wang, P. Liu, J. Hicks-Garner, et al., J. Power Sources, vol. 196, pp. 3942-3948, Apr. 2011.

[18] A. A. Hussein, IEEE Transactions on Industry Applications, vol. 51, no. 3, pp. 2321-2330, 2015. 
[19] D.-I. Stroe, M. Swierczynski, S. K. Kær, et al., IEEE Transactions on Industry Applications, vol. 54, no. 1, pp. 517-525, 2018.

[20] A. Barré, F. Suard, M. Gerard, et al., J. Power Sources, vol. 245, pp. 846 - 856, 2014.

[21] M. Ecker, N. Nieto, S. Käbitz, et al., J. Power Sources, vol. 248, pp. 839 - 851, 2014.

[22] D.-I. Stroe, M. Świerczyński, A.-I. Stan, et al., IEEE Transactions on Industry Applications, vol. 50, no. 6, pp. 4006-4017, 2014.

[23] A. Cordoba-Arenas, S. Onori, Y. Guezennec, et al., J. Power Sources, vol. 278, no. Supplement C, pp. 473 - 483, 2015.

[24] J. Kang, F. Yan, P. Zhang, et al., J. Power Sources, vol. 206, pp. $310-314,2012$.

[25] J. Kang, F. Yan, P. Zhang, et al., Energy, vol. 70, pp. $618-625,2014$.

[26] W. H. Zhu, Y. Zhu, Z. Davis, et al., Applied Energy, vol. 106, pp. 307 - 313, 2013.

[27] D. Anseán, M. González, J. Viera, et al., Journal of Power Sources, vol. 239, pp. 9 - 15, 2013.

[28] L. Ahmadi, M. Fowler, S. B. Young, et al., Sustainable Energy Technologies and Assessments, vol. 8, pp. 9 - 17, 2014.

[29] E. Redondo-Iglesias, P. Venet, and S. Pelissier in 2017 Twelfth International Conference on Ecological Vehicles and Renewable Energies (EVER), (Monaco), p. 6p, Apr. 2017.

[30] J. Jousse, E. Lemaire, N. Ginot, et al. in Industrial Electronics Society, IECON 2013 - 39th Annual Conference of the IEEE, (Vienna, Austria), pp. 1530-1535, Nov 2013.

[31] ISO12405-2:2012, Electrically propelled road vehicles - Test specification for lithium-ion traction battery packs and systems - Part 2: High-energy applications. 2012.

[32] PNGV, Battery Test Manual. U.S. Department of Energy, DOE/ID-10597 rev3. Feb. 2001.

[33] M. Petzl and M. Danzer, Energy Conversion, IEEE Transactions on, vol. 28, pp. 675-681, Sept 2013.

[34] V. Srinivasan and J. Newman, Journal of the Electrochemical Society, vol. 151, no. 10, pp. A1517A1529, 2004.

[35] T. Ohzuku, Y. Iwakoshi, and K. Sawa, Journal of the Electrochemical Society, vol. 140, pp. 24902498, September 1993.

[36] M. W. Verbrugge and B. J. Koch, Journal of the Electrochemical Society, vol. 150, no. 3, pp. A374A384, 2003.

[37] E. Redondo-Iglesias, P. Venet, and S. Pelissier, IEEE Transactions on Vehicular Technology, vol. 67, pp. 104-113, Jan 2018.

[38] M. Broussely, S. Herreyre, P. Biensan, et al., J. Power Sources, vol. 97-98, pp. 13 - 21, 2001. Proceedings of the 10th International Meeting on Lithium Batteries.

[39] M. Dubarry, C. Truchot, and B. Y. Liaw, J. Power Sources, vol. 258, pp. $408-419,2014$.

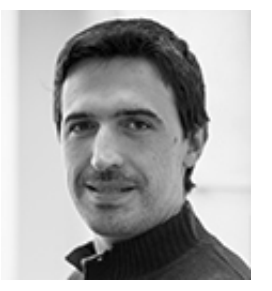

Eduardo Redondo-Iglesias was born in Vigo, Spain, in 1981. In 2009, he joined IFSTTAR in Bron, France. He is in charge of the battery test equipments in IFSTTAR. In 2017 he received the Ph.D. degree in Electrical Engineering from the University of Lyon (France) after the successful defence of his thesis entitled Study of lithium-ion batteries ageing in electric vehicle applications: Calendar and cycling ageing combination effects. His research activities are electrical modelling and characterisation of batteries and their ageing for transportation applications.

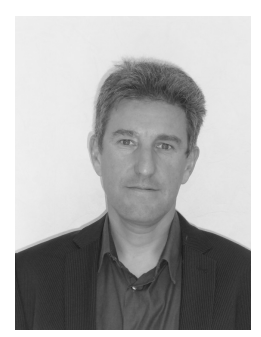

Pascal Venet was born in Aix-Les-Bains, France, in 1965. He received the Ph.D. degree in electrical engineering in 1993 from the Lyon 1 University, France. After postdoctoral positions, he joined the Lyon 1 University as Assistant Professor from 1995 to 2009.

Since 2009, he has been Professor of Electrical Engineering at the Lyon 1 University. $\mathrm{He}$ has developed his research activity in an Electrical Engineering Laboratory (AMPERE). He is responsible for the team "Secure Systems and Energy" of the laboratory.

His current research interests include characterization, modeling, fault diagnostics, reliability and ageing of energy storage systems such as batteries, supercapacitors and capacitors.

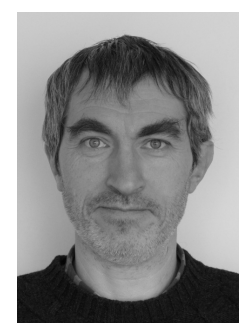

Serge Pelissier was born in 1963. He passed the agrégation of Electrical Engineering (1986) after schooling Ecole Normale Supérieure de Cachan. With a PhD in Electrical Engineering from the Institut National Polytechnique Grenoble, he first became Associate Professor and then Professor at the University of St. Etienne. His research focused on optical instrumentation, integrated optics as well as didactics of

\section{physics.}

In 2007, he joined the Laboratory Transports and Environment at INRETS (IFSTTAR since 2011) in Bron, where he is in charge of the energy storage studies. His work focuses on modeling, characterization and aging of batteries in automotive applications. Since 2013, he is the head of the Laboratory Transports and Environment. 